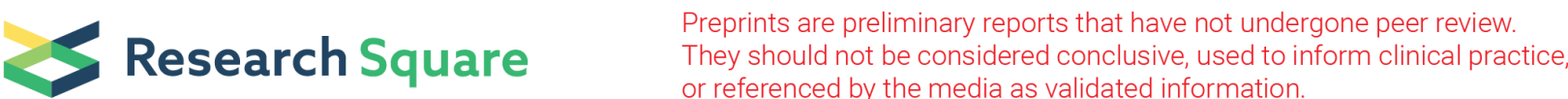

\section{Predictors of the Relationship Between the Duration of Cancer and Care Time with the Supportive Care Needs of Patients and the Quality of Life of Their Caregivers: A Path Analysis}

\section{Seyedeh Maryam Attari}

Guilan University of Medical Sciences

Zohreh mahmoodi

Alborz University of Medical Sciences

Mozhgan Mohammadzadeh Nimekari

Shahid Beheshti University of Medical Sciences School of Nursing and Midwifery

Malihe Nasiri

Shahid Beheshti University of Medical Sciences School of Nursing and Midwifery

Yaghoub Ashouri taziani

Hormozgan University of Medical Sciences

Giti Ozgoli ( $\sim$ g.ozgoli@gmail.com )

Shahid Beheshti University of Medical Sciences School of Nursing and Midwifery

\section{Research Article}

Keywords: Breast cancer, supportive care needs, quality of life, Caregiver

Posted Date: October 1st, 2021

DOI: https://doi.org/10.21203/rs.3.rs-498726/v2

License: (c) (i) This work is licensed under a Creative Commons Attribution 4.0 International License.

Read Full License 


\section{Abstract}

Background Breast cancer patients face various material, and the mutual impact of patients and caregivers on each other show the need for further supportive care from the community and family. This study aimed to identify the predictors of the direct and indirect relationships of the duration of cancer and care time with the supportive needs of the patients and the quality of life of their family caregivers.

Methods This descriptive-analytical study was carried out on 150 patients and their caregivers in Iran. Data were collected using the Supportive Care Needs Survey-short form (SCNS-SF34), the Caregiver Quality of Life Index-Cancer (CQOLC) scale, and a socio-demographic checklist and were then analyzed in SPSS-24 and Lisrel-8.8 software using descriptive-analytical statistics and path analysis.

Results The mean age of the patients and caregivers was $45.76 \pm 10.44$ and $43.46 \pm 9.5$, respectively. Based on the test results, the duration of cancer was positively correlated with the total score of supportive needs in both paths $(B=0.799)$. The patients' sexuality needs had the highest negative correlation with their duration of cancer in the direct path $(B=-0.87)$ and psychological needs the highest negative correlation in the indirect path $(\mathrm{B}=-0.32)$. The care time (in hours) had the highest positive correlation with the total score of supportive needs $(B=15.6)$ in both the direct and indirect paths, and the highest positive correlation with physical needs in the direct path $(B=10.65)$. The caregivers' quality of life had a negative and direct relationship with the duration of cancer $(B=-0.27)$ and there was a positive and direct relationship between care time and the caregivers' quality of life $(B=3.09)$.

Conclusions Duration of cancer and care time had the highest positive correlation with the patients' supportive needs, and the caregivers' quality of life had a negative correlation with the duration of cancer and a positive correlation with care time. It is therefore vital to emphasize the design and implementation of supportive care programs for breast cancer patients and their family caregivers.

\section{Introduction}

Breast cancer is the most common cancer [1,2] and the second leading cause of death in women around the world [3]. Global statistics indicate an increase in the incidence of breast cancer and its faster rise in developing countries [4], including Iran [1, 2], and have predicted a 3-fold increase in the incidence of breast cancer by 2030 [5]. The age of onset of this disease in Iran is almost a decade earlier than in developed countries [1]. Breast cancer patients face various material, physical and psychological problems; however, due to the delays in their timely referral, they are usually in the advanced stages of the disease when they begin seeking treatment [6], which necessitates the need for more supportive care from the community and families. Patients who receive greater social support have less risk of morbidity (disability) and mortality [6] and enjoy an overall better quality of life [7].

Supportive care needs can arise at any stage of illness (from diagnosis to treatment and even palliative care) and are divided into dimensions including physical, health information \& systems, emotional, social, and sexual needs [8]. Supportive care needs denote the patients' perception of their need for help and 
whether or not these needs are being met [9]. Unmet supportive care needs indicate the difference between the needed services and support with the actual services and support received $[10,11]$. One study (2017) found that nearly half of women with breast cancer had unmet needs after their diagnosis of cancer [12]. Identifying and meeting these needs helps control the symptoms and complications of the disease, increase the ability to adapt, better understand the situation, make informed decisions, and minimize dysfunction in patients [13].

According to studies, most unmet care needs in this group of patients revolve around system \& information, physical \& daily living, psychological factors, and especially care \& support and sexuality $[14,15]$.

Several factors have been suggested as predictors of increased need, including the patient's age, stage of disease progression, time since diagnosis, and level of anxiety, depression, and distress [16]. Identifying these characteristics is very important in identifying vulnerable subgroups who need more care [12].

As the family caregivers of breast cancer patients, family members play an important role in their disease management and home care delivery. The primary caregivers of women with breast cancer can play a crucial role in their adaptation to and coping with the disease at any stage of treatment as well as in supporting them in making the right decisions $[17,18]$. If caregivers are under stress and experience difficulties, family care and support will be severely hampered [19].

Cancer affects not only the quality of life of patients but also the quality of life of their caregivers [20]. The quality of life of caregivers as a result of their caregiving duties varies from the time of initial diagnosis to one and two years after diagnosis, and during this period, caregivers tend to experience greater mental burden. In care instances where more than two years have elapsed since the diagnosis, the patients and their caregivers have better adapted to the disease and enjoy a higher quality of life [21]. Caregivers focus more on the well-being of the patients, often meaning that their own health and needs are ignored [22-24]. The negative impact of care responsibilities are manifested in various forms, especially as mental and economic burdens $[22,24]$. The prevalence, severity and persistence of the burden of caregiving have a profound effect on the quality of life of the patients and the caregivers themselves [18].

In general, there is an inverse correlation between quality of life and needs [19]. Therefore, maintaining the quality of life of caregivers is associated with their ability to provide better care to patients and meet their needs [25].

Due to the growing trend of breast cancer in Iran and the referral of patients to treatment centers in advanced stages [6], the cultural diversity in the world and even in a single country, and given that patients and caregivers are mutually affected by each other, reviewing and addressing these issues are important for improving the quality of life of patients and their caregivers. Understanding the needs of caregivers is a step toward empowering patients and their caregivers. The review of literature did not yield any comprehensive studies on the direct and indirect relationship of the duration of cancer and care time 
with the supportive needs and quality of life of patients and caregivers both in one model. Therefore, this study was conducted to identify the predictors of the relationship between the duration of cancer and care time with the supportive needs of the patients and the quality of life of their family caregivers in southern Iran, so that the results can be used in plans for improving services, meeting these needs and increasing the quality of life of patients and their caregivers.

\section{Methods}

\section{Type of study}

This descriptive-analytical study examined 150 patients and 150 of their caregivers in 2019. Omid Chemotherapy and Radiotherapy Center in Bandar Abbas, Iran, was selected as the research setting. This center is the only referral center in Hormozgan Province. It covers all the patients in the cities of the province and provides them with all the relevant services, including initial diagnosis, treatment, and follow-up.

\section{Participants}

The sample size for the patients with breast cancer was determined as 140 people based on a study by Abdollahzadeh et al. [26] and considering the standard deviation of the mean score ( $\sigma$ ) and the error (d) $(z=1.96, a=0.05, d=1, \sigma=6)$. According to the following formula and a study by Sajadian et al. [27], the sample size for the family caregivers of patients with breast cancer was also determined as $140(z=1.96$, $a=0.05, d=1, \sigma=7)$. Finally, to take account of potential sample loss, 150 samples were allocated each to the groups of patients and caregivers (equation (1)).

Equation 1- sample size

$$
n=\frac{z_{\alpha / 2}^{2} \sigma^{2}}{d^{2}}
$$

The eligible women with breast cancer were selected to participate in the study.

The inclusion criteria were being 18 or older and having a definitive diagnosis of breast cancer (in any of the stages, from 1 to 4 ) with at least three months since the diagnosis, not having a known mental disorder based on the patient's records, and the ability to cooperate and answer the questions.

The inclusion criteria for the family caregivers of breast cancer patients included no self-reported history of physical and mental problems requiring treatment and being able to cooperate and answer the questions.

\section{Data collection tools}


Data were collected using the Supportive Care Needs Survey-short form (SCNS-SF34), the Caregiver Quality of Life Index-Cancer (CQOLC) scale, and a socio-demographic information checklist.

\section{The Caregiver Quality of Life Index-Cancer (CQOLC) scale}

The Caregiver Quality of Life Index-Cancer (CQOLC) scale has 35 items, which are scored based on a 5point Likert scale, and has four dimensions: Mental/emotional burden, lifestyle disruption, positive adaptation, and financial concerns. The scale scores range from 0 to 140, with higher scores denoting better quality of life. The questionnaire was translated into Persian by Khanjari et al. (28) using the forward-backward translation method and validated using face, content, and construct validity methods. The scale reliability using Cronbach's alpha method was reported to be $89 \%$. In this study, the alpha coefficient was calculated to assess internal consistency and the test-retest coefficient to assess reliability. The Cronbach alpha for the different dimensions of the scale was $0.76-0.84$ and ICC was $0.93-$ 0.98 .

\section{The Supportive Care Needs Survey-short form (SCNS-SF34)}

This questionnaire consists of 34 items scored based on a Likert scale and has five domains, including psychological needs, health system \& information, physical \& daily living, patient care \& support, and sexuality domains. The scale scores range from 0 to 100 and a higher score denotes more unmet needs.

Abdollahzadeh et al. (2014) translated the English version of the questionnaire into Persian using the forward-backward translation method. The content validity of the questionnaire was approved by a panel of 12 experts and its reliability was confirmed with Cronbach's alpha coefficient of 0.9 [26]. In this study, the alpha coefficient was calculated for internal consistency and the test-retest coefficient for reliability. The Cronbach alpha for the different dimensions of the questionnaire was $0.74-0.87$ and ICC was 0.99 .

Study procedures After obtaining the necessary permits and the code of ethics for the study, the researcher visited the mentioned center and extracted the names of all the people with breast cancer who visited every day from the reception desk. Each patient and their family caregiver were separately consulted about the research subject, and in the case of eligibility and willingness to participate in the study, informed written consent was obtained from them. The questionnaires were then distributed among the women with breast cancer and their family caregivers to complete. Sampling continued among patients in any stage of cancer treatment, from chemotherapy and hormone therapy to follow-up, until the desired sample size was reached. Data were extracted using SPSS-24 and Lisrel-8.8 software, and descriptive-analytical statistical tests and path analysis were used for the data analysis.

\section{Results}

The mean age of the patients and the caregivers was $45.76 \pm 10.44$ and $43.46 \pm 9.5$ years, respectively; the mean duration of cancer was $16.3 \pm 9.3$ months and the mean care time was $2.34 \pm 0.75$ hours (Table 1 ). 
The lowest general need for care was in the patients in the follow-up group (27.58 12.41$)$. In the chemotherapy and hormone therapy groups, the highest care needs were related to physical needs, and the lowest to sexuality. In the follow-up group, the highest need was related to supportive needs, followed by physical needs.

There was a statistically significant difference between the three groups of patients in terms of the duration of cancer. The shortest duration of cancer pertained to the chemotherapy group $(8.06 \pm 6$ months) and the longest to the follow-up group (24.02 \pm 6.87 months). There was a significant relationship between the physical needs score in the chemotherapy group and the quality of life of their caregivers $(P=0.02)$; that is, with each unit of increase in the physical needs of the patients in the chemotherapy group, the quality of life score of their caregivers decreased by $60 \%$.

The one-way ANOVA showed a statistically significant difference in the mean total score of quality of life between the caregivers of the three groups of patients $(P=0.012)$. Also, based on Tukey's post-hoc test, a significant difference was observed between the follow-up group and the chemotherapy group $(P=0.015)$.

Based on the results of the path analysis, the duration of cancer had a positive relationship in both the direct and indirect paths with the total score of supportive needs (total effect $B=0.799$ ). In other words, as the duration of cancer increased, the patients' supportive needs also increased. Among the variables that were related to the duration of cancer only in one path, sexuality had the highest negative relationship with the duration of cancer in the direct path $(B=-0.87)$ and psychological needs in the indirect path $(B=-0.32)$. In other words, when the duration of cancer was shorter, the patients had more unmet sexual and psychological needs -in other words, this dimension of the patient's supportive needs would be more unfavorable.

According to the findings, the care time in hours had the highest positive relationship with the total score of supportive needs in both the direct and indirect paths $(B=15.6)$. In the indirect path, the care time was linked to the total score of supportive needs through physical needs. In other words, when the hours of care increase, more of the supportive needs of the patient, and mostly their physical needs, are met. In the direct path, the care time had the highest relationship with physical needs $(B=10.65)$. In other words, the higher were the physical needs, the higher would be the hours of care allocated to the patient.

The quality of life of the caregivers had a direct negative correlation with the duration of cancer (B $=-0.27)$. In other words, the longer was the duration of cancer, the worse would be the quality of life of the caregivers. Also, there was a positive and direct correlation between care time and the quality of life of the caregivers (B=3.09) (Table 2).

Assessing the fit indices of the model indicate the desirability and high fit of the model, and the rationality of the relationships between the variables based on the conceptual model. Accordingly, the fitted model does not have a significant difference with the conceptual model (Table 3). 


\section{Discussion}

According to the present findings regarding the patients' supportive needs, the duration of cancer and care time or hours had the highest relationship with the total score of supportive needs in both the direct and indirect paths. Also, the caregivers' quality of life had a negative and direct relationship with the patient's duration of cancer, and a positive and direct relationship with the care time.

Meeting the physical needs of patients is of particular importance [29-31]. The positive correlation observed in the present study between physical needs and the other dimensions of supportive care needs indicates the reduction in the patients' physical needs over time. In other words, the shorter was the duration of illness, the more did the patients need psychological, sexual, and supportive care. In a study by Mohammadzadeh Nimekari (2019), physical needs and sexual needs had the highest and lowest mean scores among the patients' supportive care needs, in respective order. The psychological dimension, system \& information, and supportive dimensions had a moderate mean score. Higher scores indicated the patients' greater supportive care needs [32].

Similar to the present findings, Wang et al. [33] also found that the length of time from the diagnosis was negatively correlated with supportive care needs. A higher score of supportive care needs was observed among the women who had a shorter duration of cancer or were in the higher stages of cancer. In a study by Shahsavari et al., the most dire need of the participants in the chemotherapy stage was related to the physical dimension and the lowest to the supportive dimension.

Unmet needs can vary even in patients with the same conditions [34]. In the present study, the most common unmet needs of the patients in all the groups were related to the physical dimension. In the follow-up period, women with breast cancer had more unmet needs in the supportive dimension followed by the physical dimension, and their lowest level of supportive care needs pertained to the sexual dimension. In contrast to the present findings, some studies $[12,15,33,35]$ have reported the need for system \& information to be the most prevalent unmet need. In the present study, the decreased physical needs of the patients in the follow-up period compared to the chemotherapy period may have been because the patients had passed the active phase of treatment and its side-effects and had somewhat regained their physical strength. Abdollahzadeh examined patients four to six months after their initial treatment; also, half of the participants were recruited from patients visiting a non-governmental breast cancer support center that provided training as well [35].

In the present study, sexuality needs decreased with age. Also, a significant direct relationship was reported between the patients' age and the duration of cancer and care time. The mean duration of cancer was two years. It could be the case that the lack of a support association or institution in Bandar Abbas has made the need for support one of the greatest unmet needs in this group of patients. The reason for the difference in the results of these studies with the present study may be that, in the above studies, patients had completed the initial courses of treatment. Chemotherapy is associated with serious and non-serious drug side-effects [36, 37]. The side-effects of treatment can affect the needs of patients in the physical dimension. 
The elapse of one year from the major breast cancer treatments received is associated with a gradual increase in sexual activity in these women [38]. In the present study, the duration of cancer correlated directly with the highest score of care needs; in other words, as the duration of cancer increased, the total score of the patient's supportive needs also increased. Moreover, an increased duration of cancer was directly associated with less fulfillment of sexual needs and indirectly with less fulfillment of psychological needs. The differences in the duration of cancer in the chemotherapy, hormone therapy, and follow-up groups could be the reason for the difference in the unmet sexual needs of the patients between the three groups. The duration of cancer was $8.06 \pm 6$ months in the chemotherapy group and $24.02 \pm 6.37$ months in the follow-up group.

Socio-demographic characteristics play a clear role in predicting care needs. According to previous studies on the care needs of breast cancer patients, younger patients and patients with a sexual partner had more sexual needs $[16,39]$ and unmet physical and daily living needs [40] than the older patients. Similarly, a study by Shahsavari et al. [31] showed that the need for care decreases with age and increases with disease stage.

Asian women are generally reluctant to talk about their sexual issues and consider talking about such matters embarrassing and unreasonable [41]. It appears that the taboos about sexual issues in the Iranian society can justify the subtle role of sexual needs among patients with breast cancer. In addition, the social culture may influence the answers to the question of sexual needs.

In the efforts to cope with their caregiving burden, the caregivers of cancer patients have reported unmet needs of their own during their patient's active treatment or completion of treatment [11, 42].

In the present study, the mean total quality of life scores of the family caregivers of breast cancer patients in the three groups, i.e. the chemotherapy, hormone therapy, and follow-up groups, was $55.26 \pm 15.6$, $54.12 \pm 13.4$, and $48.10 \pm 7.9$, respectively. Meanwhile, in some studies $[43,44]$, the total quality of life score of caregivers has been reported as above $80 \%$. In the present study, the highest and lowest mean scores of the caregivers in the domains of quality of life pertained to psychological stress and financial concerns, respectively. The caregivers of cancer patients had a poor quality of life due to fatigue, anxiety, and care pressures. A study in China found that the burden of care in caregivers has an adverse effect on their quality of life, especially their mental health [45].

In contrast to the findings of some studies, the present study observed a negative and direct relationship between the caregivers' quality of life and the patients' duration of cancer (especially in patients in the follow-up period). As the hours of caring for the cancer patient increased, the score of the mental and psychological burden of caring decreased in her caregiver. Khanjari et al. investigated the caregivers of recently-diagnosed cancer patients (two to three weeks after diagnosis and six months later) [43], while in the present study, the mean care time was eight months at the very least (in the chemotherapy group). The quality of life of caregivers as a result of the care given varies from the time of diagnosis until one to two years later, and during this time, they experience greater psychological burden; meanwhile, for the 
care given to patients with more than two years since their diagnosis, both the patient and her caregiver tend to have gotten more adapted to the disease by this time [21].

Demographic characteristics such as age and gender are the most important predictors of quality of life in patients' caregivers [46]. In the study by Hashemian et al., the mean quality of life scores of caregivers were similar to the scores in the present study. In the present study, the mean age of the caregivers was $43.46 \pm 9.5$ years and most caregivers were the patients' husbands, which justifies the disparity between the present study and some other studies $[43,47,48]$. Turkoglu et al. studied the family caregivers of patients with different types of cancer [47]. In these three studies, most caregivers (60-80\%) were female, while in the present study, most caregivers were the husbands of the patients and were male.

Strengths In the present study, the supportive care needs of patients with breast cancer and the quality of life of their family caregivers were assessed simultaneously in different courses of treatment (chemotherapy and hormone therapy) and the post-treatment follow-up.

Limitations Since this research was carried out in Bandar Abbas, its results should be generalized to other parts of Iran only with caution. Also, due to the high impact of disease periods (chemotherapy, radiotherapy, and follow-up) on the supportive needs of patients, further studies with larger sample sizes are required on patients in different stages of the disease and especially in the follow-up period.

\section{Conclusion}

The results of this study showed that the patients' duration of cancer and care time had the highest positive correlation with the patients' supportive needs and that the caregivers' quality of life had a negative correlation with the duration of cancer and a positive correlation with care time. Therefore, the design and implementation of supportive care programs for breast cancer patients and their family caregivers, especially in patients undergoing chemotherapy and hormone therapy, are crucial for reducing the patients' physical needs and empowering their families. The present findings suggest the need to adopt decisions for more extensive activities in the form of associations and free counseling centers for breast cancer patients and their families, especially in the post-treatment follow-up period.

\section{Abbreviations}




\begin{tabular}{ll} 
CANCERT & Cancer time \\
\hline CARET & Care time \\
\hline QLF & Quality of life \\
\hline SEXN & Sexual needs \\
\hline PHSYN & Psychological needs \\
\hline SN & Supportive needs \\
\hline HEALTN & Health system \& information needs \\
\hline PHN & Physical needs \\
\hline SCNS-SF34 & Supportive Care Needs Survey-short form \\
\hline CQOLC & the Caregiver Quality of Life Index-Cancer
\end{tabular}

\section{Declarations}

Acknowledgments We sincerely express our gratitude to all the participants, whose cooperation with the research team enabled the implementation of this study. We also express sincere gratitude to the Research Deputy of Shahid Beheshti University of Medical Sciences for their assistance and cooperation.

Author Contributions All authors contributed to the study conception and design. Seyedeh Maryam Attari Participated in study design, drafting and the conclusion, drafting the manuscript, which was revised by Giti Ozgoli. Zohreh Mahmoodi, Participated in study design and interpretation of data and drafting the manuscript. Mozhgan Mohammadzadeh Nimekari Participated in study design, data collection. Malihe Nasiri Contributed to drafting data, evaluation and statistical analysis, and interpretation of data. Yaghoub Ashouri taziani Participated in study design, data evaluation and the conclusion. Giti Ozgoli was responsible for overall supervision, Participated in study acquisition, interpretation of data and the conclusion, revision and final approval of the manuscript. All authors read and approved the final manuscript and are accountable for all aspects of the work. All authors read and approved the final manuscript.

Funding This work was financially supported by the vice-chancellor of research affairs at Shahid Beheshti University of Medical Sciences.

\section{Compliance with ethical standards}

Competing Interests There is no conflict of interest in this study.

Ethical Approval and Consent to Participate The study began after obtaining the necessary permits and receiving a code of ethics from the Ethics Committee of Shahid Beheshti University of Medical Sciences 
(IR.SBMU.PHARMACY.REC.1400.004 on Apr. 27, 2021). All procedures performed in accordance with the ethical standards the 1964 Helsinki Declaration.

Informed consent Informed consent was obtained from all individual participants included in the study.

Availability of data and materials Data are available upon request through corresponding author.

Consent for publication This manuscript does not contain any individual person's data in any form.

\section{Author details}

${ }^{1}$ Reproductive Health Research Center, Department of Obstetrics \& Gynecology, Al-zahra Hospital, School of Medicine, Guilan University of Medical Sciences, Rasht, Iran. ${ }^{2}$ Social determinants of health reaearch center.alborz University of medical sciences.Karaj.Iran. ${ }^{3}$ Student of Reproductive Health, Student Research Committee, School of Nursing and Midwifery, Shahid Beheshti University of Medical Sciences, Tehran, Iran. ${ }^{4}$ Assistant Professor of Biostatistics, Department of Basic Sciences, School of Nursing and Midwifery, Shahid Beheshti University of Medical Sciences, Tehran, Iran. ${ }^{5}$ Department of Radiation Oncology, Shahid Mohammadi Hospital, Hormozgan University of Medical Sciences, Bandar Abbas, Iran. ${ }^{* 6}$ Associate Professor of Reproductive Health, Midwifery and Reproductive Health Research Center, Department of Midwifery and Reproductive Health, School of Nursing and Midwifery, Shahid Beheshti University of Medical Sciences, Tehran, Iran.

\section{References}

1. Afsharfard A, Mozaffar M, Orang E, Tahmasbpour E. Trends in epidemiology, clinical and histopathological characteristics of breast cancer in Iran: results of a 17 year study. Asian Pacific journal of cancer prevention : APJCP. 2013;14(11):6905-11. PubMed PMID: 24377624. Epub 2014/01/01. eng. https ://doi.org/10.7314/apjcp.2013.14.11.6905

2. Rezagholi T, Yavari P, Abolhasani F, Etemad K, Khosravi A, Hashemi Nazari S, et al. Estimating the Burden of Breast Cancer in Iranian Women in 2009. Iranian Journal of Epidemiology. 2015;10(4):3240. eng

3. Asadabadi A, Bahrampour A, Haghdoost A. Prediction of Breast Cancer Survival by Logistic Regression and Artificial Neural Network Models. Iranian Journal of Epidemiology. 2014;10(3):1-8. eng.

4. Mousavi SM, Gouya MM, Ramazani R, Davanlou M, Hajsadeghi N, Seddighi Z. Cancer incidence and mortality in Iran. Annals of oncology : official journal of the European Society for Medical Oncology. 2009 Mar;20(3):556-63. PubMed PMID: 19073863. Epub 2008/12/17. eng. https ://doi.org/10.1093/annonc/mdn642.

5. Asadzadeh Vostakolaei F, Broeders MJ, Mousavi SM, Kiemeney LA, Verbeek AL. The effect of demographic and lifestyle changes on the burden of breast cancer in Iranian women: a projection to 
2030. Breast (Edinburgh, Scotland). 2013 Jun;22(3):277-81. PubMed PMID: 22835919. Epub 2012/07/28. eng. https ://doi.org/10.1016/j.breast.2012.07.002

6. Attari SM, Ozgoli G, Solhi M, Alavi Majd H. Study of Relationship Between Illness Perception and Delay in Seeking Help for Breast Cancer Patients Based on Leventhal's Self-Regulation Model. Asian Pacific journal of cancer prevention : APJCP. 2016;17(S3):167-74. PubMed PMID: 27165252. Epub 2016/05/12. eng. http://dx.doi.org/10.7314/APJCP.2016.17.S3.167.

7. Zeighami Mohammadi S, Ghaffari F. Sexual dysfunction and its correlation with quality of life among women affected with cancer. The Iranian Journal of Obstetrics, Gynecology and Infertility. 2009;12(2):39-46.

8. Pérez-Fortis A, Schroevers MJ, Fleer J, Alanís-López P, Veloz-Martínez MG, Ornelas-Mejorada RE, et al. Psychological burden at the time of diagnosis among Mexican breast cancer patients. Psychooncology. 2017;26(1):133-6.

9. McElduff P, Boyes A, Zucca A, Girgis A. Supportive Care Needs Survey: A guide to administration, scoring and analysis. Newcastle: Centre for Health Research \& Psycho-oncology. 2004.

10. Sanson-Fisher R, Girgis A, Boyes A, Bonevski B, Burton L, Cook P. The unmet supportive care needs of patients with cancer. Supportive Care Review Group. Cancer. 2000 Jan 1;88(1):226-37. PubMed PMID: 10618627. Epub 2000/01/05. eng.

11. Chen S-C, Chiou S-C, Yu C-J, Lee Y-H, Liao W-Y, Hsieh P-Y, et al. The unmet supportive care needswhat advanced lung cancer patients' caregivers need and related factors. Supportive Care in Cancer. 2016;24(7):2999-3009.

12. Pérez-Fortis A, Fleer J, Sánchez-Sosa JJ, Veloz-Martínez MG, Alanís-López P, Schroevers MJ, et al. Prevalence and factors associated with supportive care needs among newly diagnosed Mexican breast cancer patients. Supportive Care in Cancer. 2017;25(10):3273-80.. https ://doi.org/10.1007/s00520-017-3741-5.

13. Ream E, Quennell A, Fincham L, Faithfull S, Khoo V, Wilson-Barnett J, et al. Supportive care needs of men living with prostate cancer in England: a survey. British journal of cancer. 2008 Jun 17;98(12):1903-9. PubMed PMID: 18506142. Pubmed Central PMCID: PMC2441950. Epub 2008/05/29. eng. https ://doi.org/ 10.1038/sj.bjc.6604406.

14. Doubova SV, Aguirre-Hernandez R, Gutiérrez-de la Barrera M, Infante-Castañeda C, Pérez-Cuevas R. Supportive care needs of Mexican adult cancer patients: validation of the Mexican version of the Short-Form Supportive Care Needs Questionnaire (SCNS-SFM). Supportive care in cancer : official journal of the Multinational Association of Supportive Care in Cancer. 2015 Sep;23(9):2711-9. PubMed PMID: 25663576. Epub 2015/02/11. eng. https ://doi.org/10.1007/s00520-015-2634-8.

15. Faghani S, Mohammadian R, Rahmani A, Mohajjel-Aghdam AR, Hassankhani H, Azadi A. Supportive Care Needs of Iranian Cancer Survivors and Relationships with Social Support. Asian Pacific journal of cancer prevention: APJCP. 2015;16(15):6339-45. PubMed PMID: 26434840. Epub 2015/10/06. eng. https ://doi.org/10.7314/apjcp.2015.16.15.6339. 
16. Fiszer C, Dolbeault S, Sultan S, Brédart A. Prevalence, intensity, and predictors of the supportive care needs of women diagnosed with breast cancer: a systematic review. Psychooncology. 2014 Apr;23(4):361-74. PubMed PMID: 24677334. Epub 2014/03/29. eng. https ://doi.org/10.1002/pon.3432.

17. Rabin EG, Heldt E, Hirakata VN, Bittelbrunn AC, Chachamovich E, Fleck MP. Depression and perceptions of quality of life of breast cancer survivors and their male partners. Oncology nursing forum. 2009 May;36(3):E153-8. PubMed PMID: 19403443. Epub 2009/05/01. eng. https ://doi.org/10.1188/09.onf.e153-e158.

18. Lopez V, Copp G, Molassiotis A. Male caregivers of patients with breast and gynecologic cancer: experiences from caring for their spouses and partners. Cancer nursing. 2012 Nov-Dec;35(6):402-10. PubMed PMID: 22067685. Epub 2011/11/10. eng. https ://doi.org/ 10.1097/NCC.0b013e318231daf0.

19. van den Bos GA, Triemstra AH. Quality of life as an instrument for need assessment and outcome assessment of health care in chronic patients. Quality in health care : QHC. 1999 Dec;8(4):247-52. PubMed PMID: 10847887. Pubmed Central PMCID: PMC2483673. Epub 2000/06/10. eng. https ://doi.org/ 10.1136/qshc.8.4.247

20. Obaidi JG, Al-Atiyyat NM. Quality of life among primary caregivers of women with breast cancer: A review. Middle East Journal of Cancer. 2013;4(2):45-9..

21. Kim Y, Given BA. Quality of life of family caregivers of cancer survivors: across the trajectory of the illness. Cancer. 2008;112(S11):2556-68.. https ://doi.org/ 10.1002/cncr.23449.

22. Tang ST. Predictors of the extent of agreement for quality of life assessments between terminally ill cancer patients and their primary family caregivers in Taiwan. Quality of life research. 2006;15(3):391-404.. https ://doi.org/ 10.1007/s11136-005-2158-7.

23. Schubart JR, Kinzie MB, Farace E. Caring for the brain tumor patient: family caregiver burden and unmet needs. Neuro-oncology. 2008 Feb;10(1):61-72. PubMed PMID: 17993635. Pubmed Central PMCID: PMC2600839. Epub 2007/11/13. eng. https ://doi.org/ 10.1215/15228517-2007-040.

24. Glajchen $M$. The emerging role and needs of family caregivers in cancer care. The journal of supportive oncology. 2004 Mar-Apr;2(2):145-55. PubMed PMID: 15328817. Epub 2004/08/27. eng.

25. Bahrami M, Farzi S. The effect of a supportive educational program based on COPE model on caring burden and quality of life in family caregivers of women with breast cancer. Iranian journal of nursing and midwifery research. 2014 Mar;19(2):119-26. PubMed PMID: 24834079. Pubmed Central PMCID: PMC4020019. Epub 2014/05/17. eng.

26. Abdollahzadeh F, Moradi N, Pakpour V, Rahmani A, Zamanzadeh V, Mohammadpoorasl A, et al. Unmet supportive care needs of Iranian breast cancer patients. Asian Pac J Cancer Prev [Internet]. 2014; 15(9):[3933-8 pp.]. Available from: https://www.ncbi.nlm.nih.gov/pubmed/24935576. https ://doi.org/ 10.7314/apjcp.2014.15.9.3933.

27. Sajadian A, Montazeri A. Exploring the Experiences of Iranian Women with Breast Cancer: A Qualitative Study. Iranian Journal of Epidemiology. 2011;7(2):8-16. eng. 
28. Khanjari S, Langius-Eklöf A, Oskouie F, Sundberg K. Family caregivers of women with breast cancer in Iran report high psychological impact six months after diagnosis. European Journal of Oncology Nursing [Internet]. 2014; 18(6):[630-5 pp.]. Available from:

https://www.ncbi.nlm.nih.gov/pubmed/24996513. https ://doi.org/ 10.1016/j.ejon.2014.06.002.

29. Rahmani A, Ferguson C, Jabarzadeh F, Mohammadpoorasl A, Moradi N, Pakpour V. Supportive care needs of Iranian cancer patients. Indian journal of palliative care. 2014 Sep;20(3):224-8. PubMed PMID: 25191012. Pubmed Central PMCID: PMC4154172. Epub 2014/09/06. eng. https ://doi.org/ 10.4103/0973-1075.138400.

30. Edib Z, Kumarasamy V, Binti Abdullah N, Rizal A, Al-Dubai SAR. Most prevalent unmet supportive care needs and quality of life of breast cancer patients in a tertiary hospital in Malaysia. Health and quality of life outcomes. 2016;14(1):26.. https ://doi.org/ 10.1186/s12955-016-0428-4.

31. Shahsavari M, Bolourchifard F, llkhani M, Shakeri N, Safavibayat Z. The supportive care needs of Iranian women with breast cancer treated with chemotherapy. International Journal of Advanced Biotechnology and Research. 2016;7(4):1641-9..

32. Mohammadzadeh Nimekari M, Saei Ghare Naz M, Ashouri Taziani Y, Nasiri M, Evazi MR, Shafizad A, et al. Correlation between Supportive Care Needs of Women with Breast Cancer and Quality of Life of their Family Caregivers. International journal of community based nursing and midwifery. 2019 Oct;7(4):300-8. PubMed PMID: 31641679. Pubmed Central PMCID: PMC6779921. Epub 2019/10/24. eng. https ://doi.org/ 10.30476/ijcbnm.2019.73892.0.

33. Wang H-M, Beyer M, Gensichen J, Gerlach FM. Health-related quality of life among general practice patients with differing chronic diseases in Germany: cross sectional survey. BMC Public Health. 2008;8(1):246.. https ://doi.org/ 10.1186/1471-2458-8-246.

34. Sanson-Fisher R, Carey M, Paul C, editors. Measuring the unmet needs of those with cancer: a critical overview. Cancer Forum; 2009: The Cancer Council Australia.

https://search.informit.org/doi/10.3316/informit.717040667296546.

35. Abdollahzadeh F, Moradi N, Pakpour V, Rahmani A, Zamanzadeh V, Mohammadpoorasl A, et al. Unmet supportive care needs of Iranian breast cancer patients. Asian Pacific Journal of Cancer Prevention. 2014;15(9):3933-8.. https ://doi.org/10.7314/apjcp.2014.15.9.3933.

36. Antony A, Joel J, Shetty J, Umar M. Identification and analysis of adverse drug reactions associated with cancer chemotherapy in hospitalized patient. Int J Pharm Pharmaceut Sci 2016. 2016;6:3-7. .

37. Fani Pakdel A, Elyasi S, Kooshiar MM, Jannati Yazdan Abad M, Marouzi A, Asgarian M. Identification and analysis of adverse drug reactions associated with colorectal and gastric cancer chemotherapy in hospitalized patients. medical journal of mashhad university of medical sciences. 2018;61(2):92130.

38. Yang EJ, Kim S-W, Heo C-Y, Lim J-Y. Longitudinal changes in sexual problems related to cancer treatment in Korean breast cancer survivors: a prospective cohort study. Supportive Care in Cancer. 2011;19(7):909-18.. https ://doi.org/ 10.1007/s00520-010-0885-y. 
39. Schmid-Büchi S, Halfens RJ, Müller M, Dassen T, van den Borne B. Factors associated with supportive care needs of patients under treatment for breast cancer. European journal of oncology nursing: the official journal of European Oncology Nursing Society. 2013 Feb;17(1):22-9. PubMed PMID: 22449715. Epub 2012/03/28. eng. https ://doi.org/ 10.1016/j.ejon.2012.02.003

40. Griesser AC, Vlastos G, Morel L, Beaume C, SAPPINO AP, Haller G. Socio-demographic predictors of high support needs in newly diagnosed breast cancer patients. European journal of cancer care. 2011;20(4):466-74.. https ://doi.org/ 10.1111/j.1365-2354.2010.01190.x

41. Fobair P, Stewart SL, Chang S, D'Onofrio C, Banks PJ, Bloom JR. Body image and sexual problems in young women with breast cancer. Psycho-oncology. 2006 Jul;15(7):579-94. PubMed PMID: 16287197. Epub 2005/11/16. eng. https ://doi.org/ 10.1002/pon.991.

42. Sklenarova H, Krümpelmann A, Haun MW, Friederich HC, Huber J, Thomas M, et al. When do we need to care about the caregiver? Supportive care needs, anxiety, and depression among informal caregivers of patients with cancer and cancer survivors. Cancer. 2015 May 1;121(9):1513-9. PubMed PMID: 25677095. Epub 2015/02/14. eng. https ://doi.org/ 10.1002/cncr.29223

43. Khanjari S, Langius-Eklöf A, Oskouie F, Sundberg K. Family caregivers of women with breast cancer in Iran report high psychological impact six months after diagnosis. European journal of oncology nursing : the official journal of European Oncology Nursing Society. 2014 Dec;18(6):630-5. PubMed PMID: 24996513. Epub 2014/07/06. eng. https ://doi.org/ 10.1016/j.ejon.2014.06.002.

44. Fong EJ, Cheah WL. Unmet Supportive Care Needs among Breast Cancer Survivors of CommunityBased Support Group in Kuching, Sarawak. International journal of breast cancer. 2016;2016:7297813. PubMed PMID: 27239346. Pubmed Central PMCID: PMC4863116. Epub 2016/05/31. eng. https ://doi.org/ 10.1155/2016/7297813

45. Zhu P, Fu JF, Wang B, Lin J, Wang Y, Fang NN, et al. Quality of life of male spouse caregivers for breast cancer patients in China. Asian Pacific journal of cancer prevention : APJCP. 2014;15(10):4181-5. PubMed PMID: 24935367. Epub 2014/06/18. eng. https ://doi.org/ 10.7314/арjср.2014.15.10.4181

46. Meyers JL, Gray LN, editors. The relationships between family primary caregiver characteristics and satisfaction with hospice care, quality of life, and burden. Oncology Nursing Forum; 2001.

47. Turkoglu N, Kilic D. Effects of care burdens of caregivers of cancer patients on their quality of life. Asian Pacific journal of cancer prevention : APJCP. 2012;13(8):4141-5.. https ://doi.org/ 10.7314/apjcp.2012.13.8.4141

48. Warapornmongkholkul A, Howteerakul N, Suwannapong N, Soparattanapaisarn N. Self-efficacy, social support, and quality of life among primary family-member caregivers of patients with cancer in Thailand. Journal of Health Research. 2018.

\section{Tables}

Table 1. The sociodemographic characteristics of the patients and their caregivers 


\begin{tabular}{|llll|}
\hline variables & & Mean \pm SD & Mean \pm SD \\
\hline Age & $45.76 \pm 10.44$ & $43.46 \pm 9.5$ \\
\hline Duration of cancer (months) & & $16.3 \pm 9.3$ & - \\
\hline Care time (hours) & & N(\%) & N(\%) \\
\hline Gender of caregivers & Female & - & $38(25.3)$ \\
\cline { 2 - 4 } & Male & - & $112(74.7)$ \\
\hline Stage of cancer & Level 1 & $2(1.3)$ & - \\
\cline { 2 - 4 } & Level 2 & $67(45)$ & - \\
\cline { 2 - 4 } & Level 3 & $77(51)$ & - \\
\cline { 2 - 4 } & Level 4 & $4(2.7)$ & - \\
\hline Relationship with the patient & Susband & - & $99(66)$ \\
\hline & Sister & - & $13(8.7)$ \\
\hline & Daughter & - & $24(16)$ \\
\hline & Son/Brother & - & $8(5.3)$ \\
\hline & Mother/Father & - & $6(4)$ \\
\hline & & & \\
\hline
\end{tabular}

Table 2. The direct and indirect effects of cancer duration and care time on the patients' supportive needs and their caregivers' quality of life 


\begin{tabular}{|c|c|c|c|c|c|c|}
\hline \multicolumn{3}{|l|}{ Variable } & \multirow{2}{*}{$\begin{array}{l}\text { Direct } \\
\text { Effect } \\
-0.61\end{array}$} & \multirow{2}{*}{$\begin{array}{l}\text { Indirect } \\
\text { Effect } \\
-\end{array}$} & \multirow{2}{*}{$\begin{array}{l}\begin{array}{l}\text { Total } \\
\text { Effect }\end{array} \\
-0.61\end{array}$} & \multirow{2}{*}{$\begin{array}{l}\text { T- Value } \\
\text { (for Direct) } \\
3.22\end{array}$} \\
\hline Duration of & & Physical needs & & & & \\
\hline & needs & $\begin{array}{l}\text { Psychological } \\
\text { needs }\end{array}$ & $-0.07 *$ & -0.32 & -0.32 & \\
\hline & & Sexual needs & -0.87 & - & -0.87 & 3.31 \\
\hline & & $\begin{array}{l}\text { System \& } \\
\text { information needs }\end{array}$ & $0.05^{\star}$ & -0.219 & -0.219 & 0.38 \\
\hline & & $\begin{array}{l}\text { Total score of } \\
\text { supportive needs }\end{array}$ & 1 & -0.201 & 0.799 & 3.67 \\
\hline & Quality of li & e caregivers & -0.27 & - & -0.27 & 2.40 \\
\hline \multirow[t]{6}{*}{ Care time } & \multirow{5}{*}{$\begin{array}{l}\text { Patients' } \\
\text { supportive } \\
\text { needs }\end{array}$} & Physical needs & 10.65 & - & 10.65 & 4.51 \\
\hline & & $\begin{array}{l}\text { Psychological } \\
\text { needs }\end{array}$ & 3.12 & 3.94 & 7.06 & 1.98 \\
\hline & & Sexual needs & $2.66^{\star}$ & - & - & 0.77 \\
\hline & & $\begin{array}{l}\text { System \& } \\
\text { information needs }\end{array}$ & 6.36 & 3.83 & 10.19 & 3.58 \\
\hline & & $\begin{array}{l}\text { Total score of } \\
\text { supportive needs }\end{array}$ & 12.09 & 3.51 & 15.6 & 3.43 \\
\hline & \multicolumn{2}{|c|}{ Quality of life of the caregivers } & 3.09 & - & 3.09 & 2.19 \\
\hline
\end{tabular}

Table 3. Model fit indices

\begin{tabular}{|llllllll|}
\hline Fit Index & $\mathbf{X}^{2}$ & df & $\mathbf{X}^{2} / \mathrm{df}$ & CFI & GFI & NFI & RMSEA \\
\hline Model Index & 22.04 & 14 & 1.57 & 0.97 & 0.97 & 0.94 & 0.063 \\
\hline
\end{tabular}

\section{Figures}




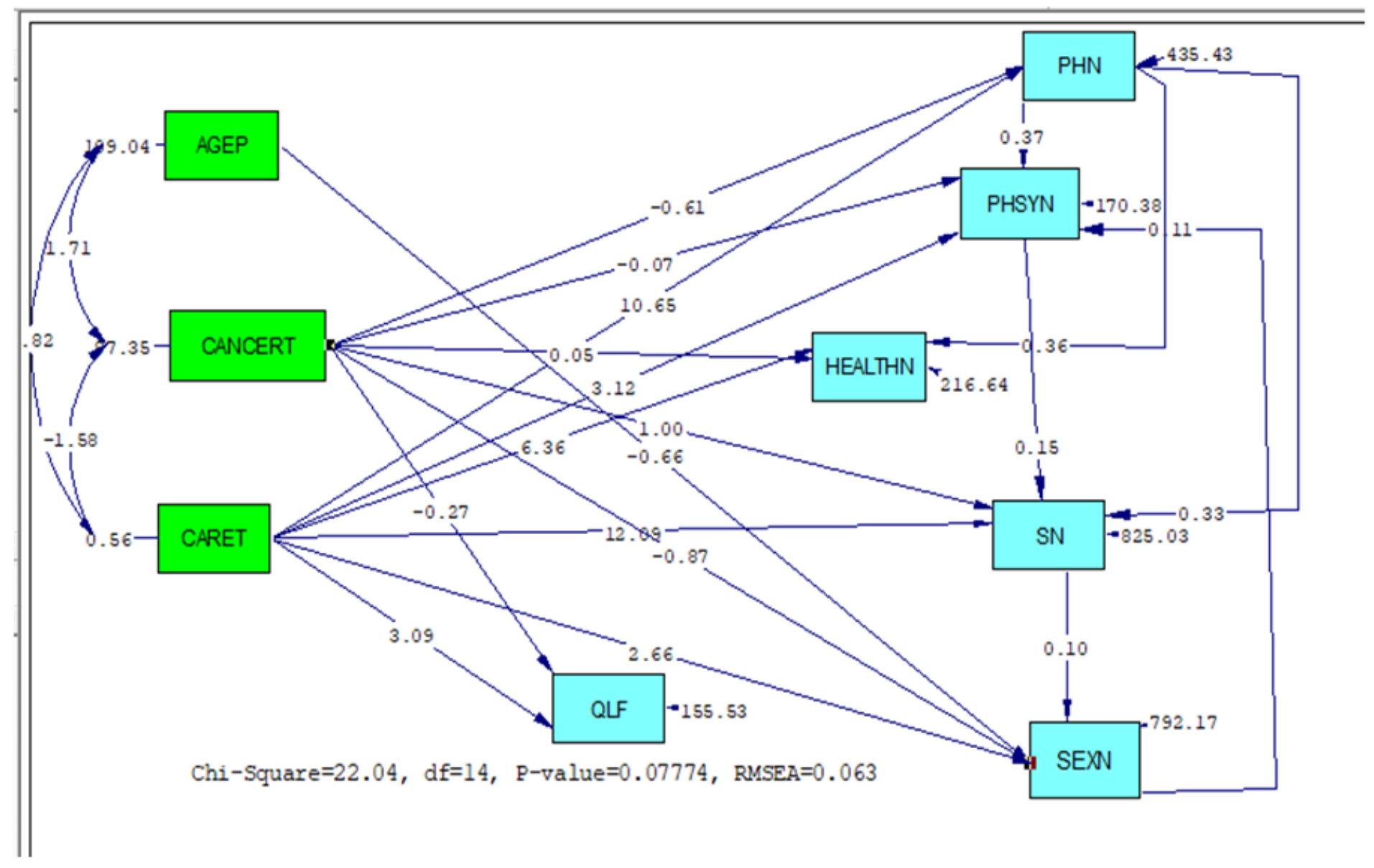

\section{Figure 1}

The path analysis model of the relationship of cancer duration and care time with the patients' supportive needs and the caregivers' quality of life. CANCERT=Cancer time CARET=Care time QLF=Quality of life SEXN= Sexual needs PHSYN=Psychological needs; $S N=$ Supportive needs; HEALTN=Health system \& information needs; $\mathrm{PHN}=$ Physical needs 